\title{
Dithienylethene Based Photochromic Siloles: a Straightforward and Divergent Synthetic Strategy
}

\author{
[a] Dr M. Devillard, N. Nour Eddine, M. Cordier, Dr G. Alcaraz \\ ISCR (Institut des Sciences Chimiques de Rennes) - UMR 6226 \\ Univ Rennes, CNRS \\ F-35000 Rennes \\ E-mail: marc.devillard@univ-rennes1.fr \\ gilles.alcaraz@univ-rennes1.fr
}

Marc Devillard, ${ }^{*}$ Nour Nour Eddine, Marie Cordier and Gilles Alcaraz*

\begin{abstract}
A straightforward synthetic methodology for the preparation of photochromic siloles based on the dithienylethene motif is developed. It relies upon an efficient palladium-catalyzed annulation reaction of a 2,3-bis(3-thienyl)-silirene with terminal alkynes in mild conditions. The reaction is functional group-tolerant and can be performed in high yields with a variety of functional terminal alkynes. It can even be extended to a polymeric polypropargylmethacrylamide (PPMA) substrate affording the corresponding photochromic polymer with different degree of photochromic unit incorporation by simply adjusting the polymer / silirene stoichiometric ratio.
\end{abstract}

In the last forty years, organic photochromic compounds have undergone tremendous development and are now essential in many aspects of our modern daily life. By taking advantage of their switching ability, they led to significant applications, particularly in the optical industry with organic photochromic lenses and glasses. ${ }^{[1]}$ This important breakthrough on the world market does not stop there and many research fields such as optoelectronic logic circuitry, data storage and other hi-tech functions are now benefiting from the growing development of photochromic molecules, of their intrinsic properties, and of their ability to be prepared and processed to produce smart materials and polymers. ${ }^{[2]}$ Fulfilling the indispensable specifications for their use in molecular electronic, diarylethene derivatives (DAEs) and among them dithienylethenes (DTEs) appeared as a promising compounds family. Initially developed by Irie and co-workers they have received a particular attention due to their excellent photochromic properties generally combining high thermal stability and good fatigue resistance. ${ }^{[3]}$ They result from the connection of two thiophene or related units to mainly a perfluorocyclopentene bridge, the modification of this ensemble constituting to date the bridgehead from which the modulation of the optical properties and the processability is generally led. ${ }^{[3-4]}$ In this context, the synthetic approaches are largely dominated by the extensive functionalization of the two thiophene units via more or less convergent and tedious syntheses that must be generally adapted on a case-by-case basis. The strategies aiming at incorporating a modified bridging cycloalkene in DTEs remains comparatively underdeveloped requiring specific approaches and tailored substrates. They are often of reduced scope and restricted to a relatively limited number of examples featuring an unsaturated heterocycle in place of the ubiquitous hexafluorocyclopent-1-ene-1,2-diyl. ${ }^{[5]}$ Simple and viable synthetic approaches for the divergent production of these molecules are scarce and their development therefore is strongly desirable.

We have now developed an efficient and straightforward synthesis of photochromic silole-embeded DTEs involving a palladium-catalyzed [3+2] annulation reaction of a silirene with terminal alkynes. Our study illustrates the versatility of this reaction that takes advantage of the abundant terminal alkynes pool and offers a good functional group tolerance. Additionally, we show it can be easily transposed to the preparation of custom photochromic polymers incorporating silole-embeded DTEs as a proof of concept.

The strategy we have chosen is based on the facile $\mathrm{Si}-\mathrm{C}$ activation of constrained silirene heterocycles and their subsequent insertion reactivity towards unsaturated organic molecules as first observed by Seyferth and also by Belzner in their seminal studies, ${ }^{[6]}$ and later developed by Woerpel for the synthesis of silicon containing heterocycles. ${ }^{[7]}$ We hypothesized that tailored silirenes could be valuable precursors in click-like chemistry reactions for the synthesis of photochromic DTEs derived from unsymmetrical 2,3-dithienyl-siloles. The targeted 2,3-dithienylsilirene precursor $\mathbf{3}$ was readily obtained by silylene transfer reaction from a silirane $\mathbf{1}$ to dithienylacetylene $\mathbf{2}$ under thermal conditions (Figure 1). $\mathbf{3}$ was isolated at the gram scale in $42 \%$ yield after crystallisation and fully characterized by multinuclear NMR spectroscopy. In the ${ }^{29} \mathrm{Si} \mathrm{NMR}$, silirene 3 displays a characteristic high field-shifted singlet at $\delta$-69.9. ${ }^{[8]}$

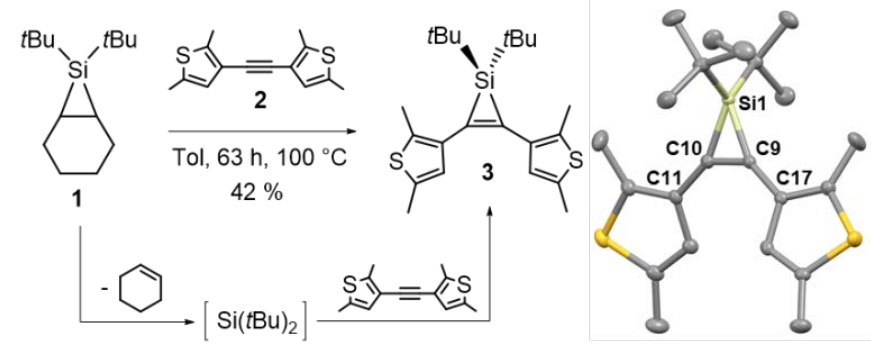

Figure 1. Synthesis of $\mathbf{3}$ by in situ trapping of a transitory silylene (left). X-ray structure of 3 (right). hydrogen atoms are omitted for clarity. Selected bond lengths $(\AA)$ and angles $\left({ }^{\circ}\right)$ : C11-C10 1.456(2), C10-C9 1.352(2), C9-C17 1.454(2), Si1-C10 1.8228(17), Si1-C9 1.8185(17); C10-Si1-C9 43.58(7); C17C9-C10-C11 43.58(7) 
The X-ray structure of 3 was determined at $150 \mathrm{~K}$ (Figure 1). The intracyclic Si-C [1.8185(17) $\AA$ and 1.8228(17) $\AA]$ distances and the distinctly short $\mathrm{C}-\mathrm{C}[1.352(2) \AA]$ bond within the threemembered ring are consistent with a silacyclopropene formulation whose metrics are comparable with those of the few silirene structures reported to date. ${ }^{[9]}$

We then investigated the stoichiometric reaction of silacyclopropene $\mathbf{3}$ with phenylacetylene under catalysis conditions. Monitoring of the reaction by multinuclear NMR revealed that a clean reaction takes place in the presence of a catalytic amount of palladium(0) tetrakis(triphenylphosphine) with gradual consumption of the starting materials and complete formation of dithienylsilole 4 after $10 \mathrm{~h}$ at $50{ }^{\circ} \mathrm{C}$ (Scheme 1a). In the ${ }^{29} \mathrm{Si}$ NMR, silole 4 exhibits a low-field shifted resonance signal at $\delta 17.2$ compared to $\mathbf{3}(\Delta \delta=+87.3 \mathrm{ppm})$ which is in the range of neutral siloles. ${ }^{[10]}$ Work-up and purification by silica gel column chromatography led to pure $\mathbf{4}(84 \%$ isolated yield) that could be fully characterized.

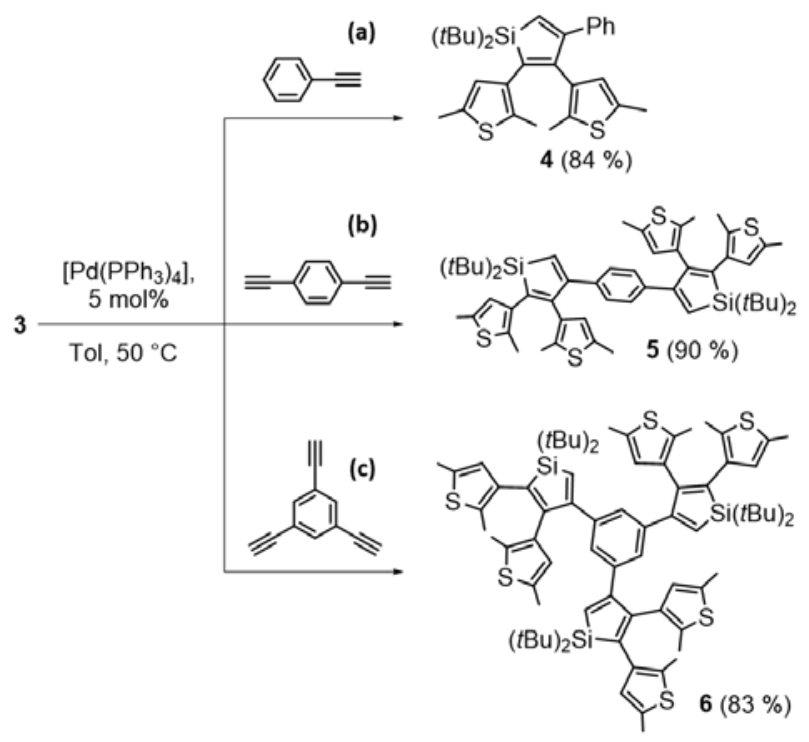

Scheme 1. Pd-catalyzed synthesis of DTEs 4,5 and 6 from 3 and (a) phenylacetylene, (b) 1,4-diethynyl- and (c) 1,3,5-triethynyl-benzene, respectively.

The reactivity of $\mathbf{3}$ toward organic substrates containing multiple alkyne functionalities was also evaluated and we were pleased to see that both di-DTE 5 and tri-DTE 6 (Scheme 1b and 1c) could be obtained cleanly following the same methodology showing the low steric dependence of the synthetic approach. DTEs $\mathbf{5}$ and $\mathbf{6}$ could be analogously isolated and fully characterized by standard spectroscopic methods and X-ray diffraction analysis (Figure 2).

The solution behaviour of the model DTE $\mathbf{4}$ under light irradiation was then assessed (Figure 3a). Before irradiation, the electronic absorption spectrum of $\mathbf{4}$ in dichloromethane displays a rather weak band at $\lambda 334 \mathrm{~nm}$ as well as absorptions bands at higher energy. Under UV light irradiation at $350 \mathrm{~nm}$, one new absorption band at $\lambda 452 \mathrm{~nm}$ characteristic of the closed isomer 4c appeared along with a colour change from colourless to yellow (Figure $3 b$ ). Based on TD-DFT calculations at the CAM$B 3 L Y P / 6-31+g(d, p)$ level of theory, this band was attributed to a
HOMO $\rightarrow$ LUMO transition mainly located on the octatetraene linkage (Figure 3c).

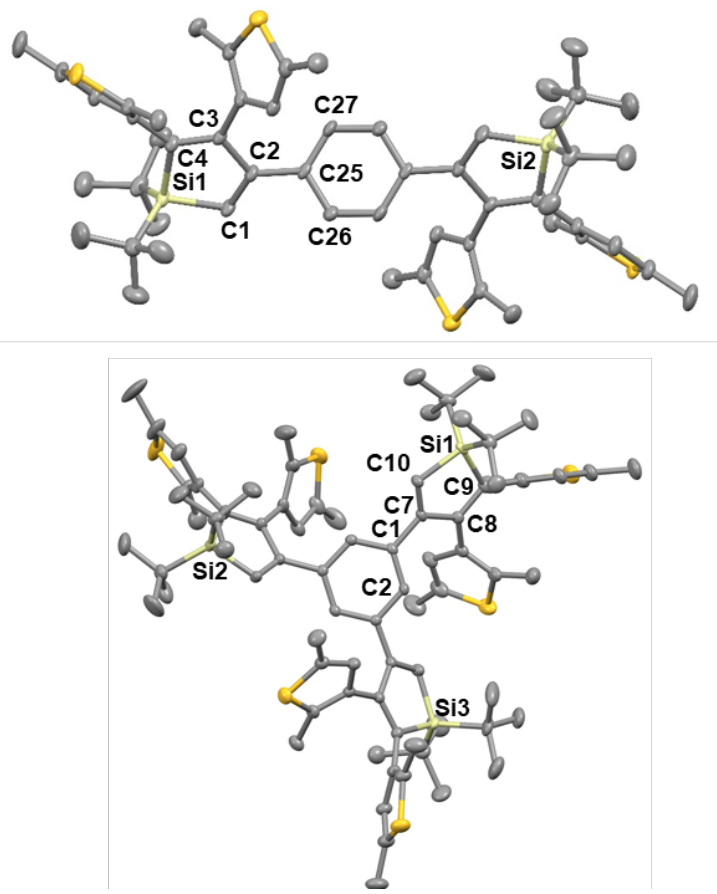

Figure 2. X-ray structure of $\mathbf{5}$ (up) and $\mathbf{6}$ (bottom). hydrogen atoms and solvent molecules are omitted for clarity. Selected bond lengths $(\AA)$ and angles $\left({ }^{\circ}\right)$ for 5: Si1-C1 1.855(3), C1-C2 1.342(4), C2-C3 1.514(4), C3-C4 1.367(4), C4-Si1 1.886(3), Si1-C5 1.909(3), Si1-C9 1.909(4); C1-C2-C25-C26 39.70(4) ; for 6 : C8-C9 1.364(3), C7-C8 1.506(3), C7-C10 1.352(3), C10-Si1 1.859(2), Si1-C9 1.895(2), Si1-C9 1.909(4); C2-C1-C7-C10 -140.1(2).

(a)

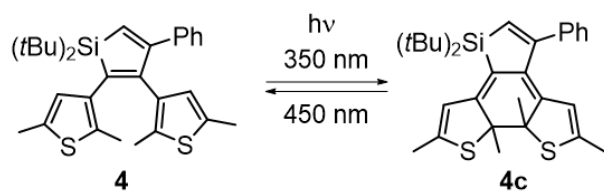

(b)

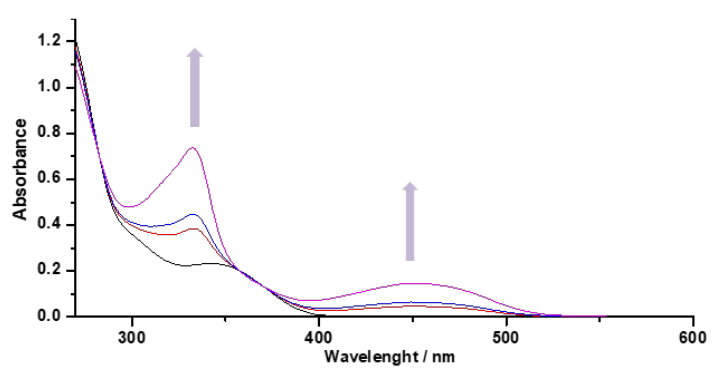

(c)

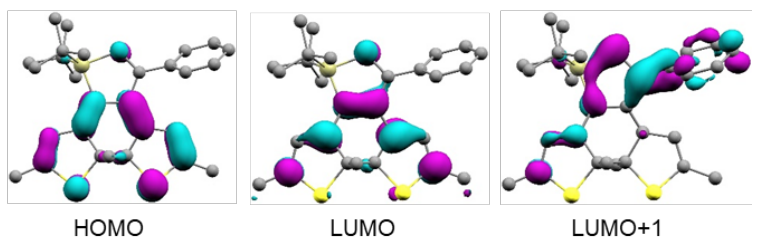

Figure 3. Reversible transformation of 4 into $\mathbf{4 c}$ under light irradiation. (a) UV vis spectral changes upon irradiation of a solution of 4 in dichloromethane at $\lambda$ $350 \mathrm{~nm}$; (b) HOMO, LUMO and LUMO+1 of $4 \mathrm{c}$ (isovalue $=0.045$ ). 
Another intense absorption is observed at $\lambda 332 \mathrm{~nm}$ which was attributed to a transition from the HOMO to a low-lying orbital of $\pi$ symmetry located on the silole ring ${ }^{[11]}$ (HOMO $\rightarrow$ LUMO+1).

The photochromic reaction is reversible and $\mathbf{4 c}$ returns to $\mathbf{4}$ under visible light irradiation ( $\lambda 450 \mathrm{~nm}$ ) ascertaining the photochromic behaviour of this new DTE.

The validity of our approach being demonstrated, we have evaluated the robustness of this two-atom-insertion synthetic methodology regarding the functional groups tolerance in order to extend the scope of this reaction for a more viable application. Starting from 3, the obtention of 2,3-dithienylsiloles with peripheral amino-, hydroxyl- or amido group was first investigated both from propargylamine, propargylalcohol and propargylamide that proved reactive in the same conditions affording quantitatively the corresponding dithienylethenes 7, 8 and 9 (Figure 4). These new functionalized DTE have been fully characterized and the X-ray crystal structure analysis of $\mathbf{8}$ definitely confirms the presence of the amino group in the structure.

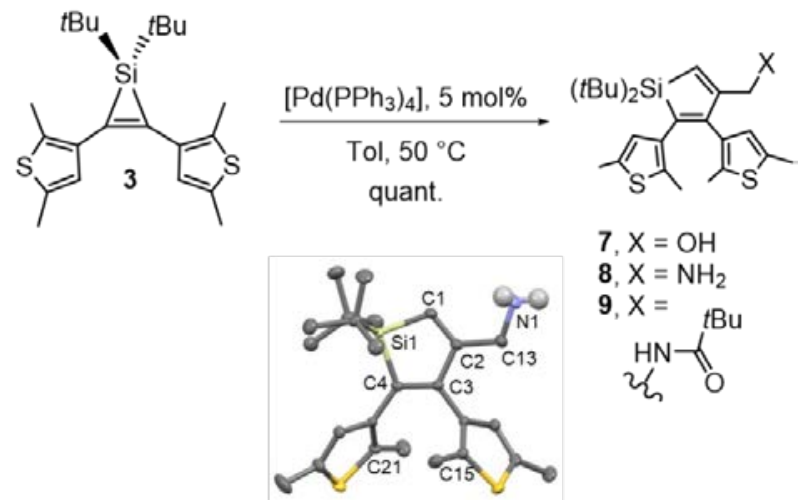

Figure 4. Pd-catalyzed synthesis of DTEs 7, 8 and 9 from propargyl-amine, alcohol and -amide, respectively (top). X-ray structure of $\mathbf{8}$ (bottom).

The scope of the reaction was finally extended to the preparation of photochromic polymers by postfunctionalization, and silirene 3 was reacted under similar conditions with organosoluble polypropargylmethacrylamide (PPMA) that displays pendent propargylamide groups. ${ }^{[12]}$ When performed in a $0.85: 1$ silirene:propargylamide stoichiometric ratio, the NMR analysis of the reaction mixture shows the complete disappearance of the sharp silirene signals and the appearance of broad resonances characteristic of a polymeric structure. ${ }^{[13]}$ After evaporation of the solvent and washing with pentane, polymer $10^{0.85}$ could be isolated as a brown powder. ${ }^{[14]}$ In the ${ }^{29} \mathrm{Si}$ NMR, the spectrum displays a single broad resonance signal at $\delta 17.4$ confirming the presence of the silole moiety. The successful incorporation of silicon in the polymer was further confirmed by size exclusion chromatography that shows a clear increase in the molecular weight from $M_{n}=6670 \mathrm{~g} \cdot \mathrm{mol}^{-1}$ to $M_{n}=27702$ g.mol ${ }^{-1}$. By varying the relative amount of 3 with respect to the propargyl groups in the starting PPMA (0.09:1 and $0.27: 1)$, two more polymers $10^{0.09}\left(\mathrm{M}_{\mathrm{n}}=10483 \mathrm{~g} . \mathrm{mol}-1\right)$ and $10^{0.27}$ $\left(M_{n}=16383\right.$ g.mol-1) have been respectively obtained (Scheme 2).

The thermal analysis of the polymers shows a lower glass transition temperature $T_{\mathrm{g}}$ for the polymers $10\left(93<T_{\mathrm{g}}<200^{\circ} \mathrm{C}\right)$ compared to the starting PPMA $\left(226^{\circ} \mathrm{C}\right.$ ). (See S11-S12 in the Supporting Information).

Upon light irradiation at $350 \mathrm{~nm}$, dichloromethane solutions of the polymers turn yellow reversibly with the appearance of an absorption band centred around 450-455 nm in agreement with the presence of the DTE closed isomer with a decreasing intensity $\left(10^{0.85}>10^{0.27}>10^{0.09}\right)$ that follows the ratio of the photochromic units within the polymer (see S14 and S15 in the Supporting Information).
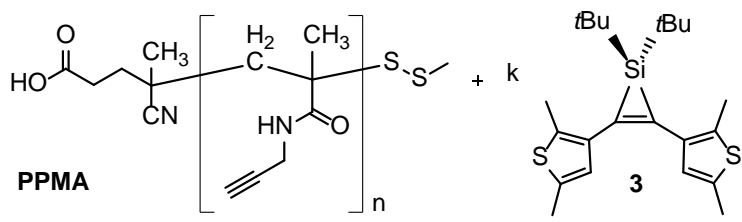

$\left[\mathrm{Pd}\left(\mathrm{PPh}_{3}\right) 4\right], 5 \mathrm{~mol} \% \downarrow \mathrm{THF}, 50{ }^{\circ} \mathrm{C}$

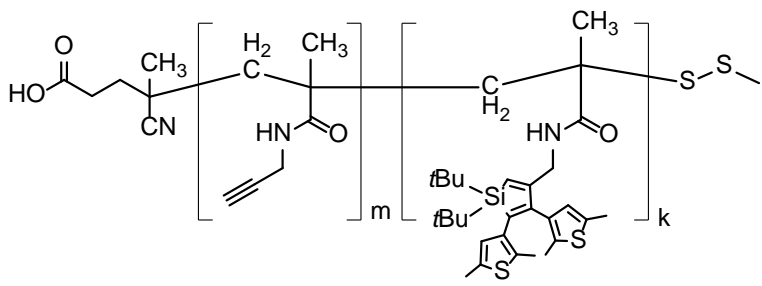

$$
\left.\begin{array}{l}
10^{0.85}, \mathrm{~m}=0.15, \mathrm{k}=0.85 \\
10^{0.27}, \mathrm{~m}=0.73, \mathrm{k}=0.27 \\
10^{0.09}, \mathrm{~m}=0.91, \mathrm{k}=0.09
\end{array}\right\} \mathrm{m}=\mathrm{n}-\mathrm{k}
$$

Scheme 2. Postfunctionalization of PPMA and synthesis of silole-containing 10 by varying the relative amount of 3 .

In conclusion, we have described here a simple and divergent method to access DTE based photochromic siloles. The reaction consists in a palladium-catalyzed [3+2] annulation reaction between the DTE derived silacyclopropene $\mathbf{3}$ and terminal alkynes. This straightforward approach enables the preparation of a variety of DTE based photochromic siloles in a single step benefiting from the abundant pool of terminal alkynes. In that respect, we have shown that the reaction operates analogously with mono- or polyalkynes enabling the one-step preparation of the corresponding silicon containing mono-, diand tri-DTEs in high yields. This synthetic approach is tolerant to protic functional groups and the alcohol, amine or amide functionalized photochromic units can be successfully and quantitatively prepared. It can be even extended to the preparation of photochromic polymers by postpolymerization modification of polypropargylmethacrylamide (PPMA) for which different degree of photochromic unit incorporation can be accessed by simply adjusting the PPMA/silacyclopropene stoichiometric ratio. This strategy gives rise to an easy access to light-responsive polymers for which studies are currently underway.

CCDC 2062247 (3), 2062248 (5), 2062249 (6) and 2062250 (8) contain the supplementary crystallographic data for this paper. They can be obtained free of charge from the Cambridge Data Centre via www.ccdc.cam.ac.uk/data request/cif. 


\section{Acknowledgements}

We thank Dr. P. Jéhan and F. Lambert (CRMPO, Rennes) for the HR-MS, Jérôme Ollivier for the GPC, C. Orione (CRMPO, Rennes) for the ${ }^{29} \mathrm{Si}$ NMR analyses and N. Audebrand and S. Freslon for the thermal analyses. N. Nour Eddine thanks the ANR (TACTIL ANR-19-CE06-0022) for a predoctoral fellowship.

Keywords: silicon $\bullet$ heterocycles $\bullet$ annulation $\bullet$ catalysis $\bullet$ photochroms

[1] a) Molecular Switches, second edition, Vol. 1 \& 2 (eds.: Ben L. Feringa, Wesley R. Browne), Wiley - VCH Verlag GmbH \& Co. KGaA, 2011; b) New Frontiers in Photochromism (eds.: M. Irie Y. Yokoyama, T. Seki), Springer Japan, Tokyo, 2013; c) Photochromic Materials: Preparation, Properties and Applications (eds.: H. Tian, J. Zhang), Wiley - VCH Verlag $\mathrm{GmbH} \&$ Co. KGaA, Weinheim, 2016.

[2] a) C. Peterson, M. A. Hillmyer, ACS Appl. Polym. Mater. 2019, 1, 2778-2786; b) A. Abdollahi, H. Roghani-Mamaqani, B. Razavi, Prog. Polym. Sci. 2019, 98, 101149; c) A. Bobrovsky, V. Shibaev, M. Cigl, V. Hamplová, P. Dorovatovskii, B. Ostrovskii, A. Bubnov, Liq. Cryst. 2020, 47, 377-383.

[3] a) M. Irie, Chem. Rev. 2000, 100, 1685-1716; b) M. Irie, T. Fukaminato, K. Matsuda, S. Kobatake, Chem. Rev. 2014, 114, 12174-12277.

[4] a) A. Perrier, F. Maurel, J. Aubard, J. Photochem. Photobiol. A 2007, 189, 167-176; b) A. Fihey, A. Perrier, F. Maurel, J. Photochem. Photobiol. A 2012, 247, 30-41.

[5] a) V. W.-W. Yam, J. K.-W. Lee, C.-C. Ko, N. Zhu, J. Am. Chem. Soc. 2009, 131, 912-913; b) Z. Li, J. Xia, J. Liang, J. Yuan, G. Jin, J. Yin, G.-A. Yu, S. H. Liu, Dyes Pigm. 2011, 90 290-296; c) B. M. Neilson, C. W. Bielawski, J. Am. Chem. Soc. 2012, 134, 12693-12699; d) B. M. Neilson, C. W. Bielawski, Chem. Commun. 2013, 49, 5453-5455; e) A. J. Teator, Y. Tian, M. Chen, J. K. Lee, C. W. Bielawski, Angew. Chem. Int. Ed. Engl. 2015, 54, 11559-11563; f) Y. Chen, D. X. Zeng, M. G. Fan, Org. Lett. 2003, 5, 1435-1437; g) C.-T. Poon, W. H. Lam, H.-L. Wong, V. W.-W. Yam, J. Am. Chem. Soc. 2010, 132, 13992-13993; h) C. T. Poon, W. H. Lam, V. W. Yam, J. Am. Chem. Soc. 2011, 133, 19622-19625; i) J. C. Chan, H. L. Wong, W. T. Wong, V. W. Yam, Chem. Eur. J. 2015, 21, 69366948; j) V. Lemieux, M. D. Spantulescu, K. K. Baldridge, N. R. Branda, Angew. Chem. Int. Ed. Engl. 2008, 47, 5034-5037; k) J. T. Price, P. J. Ragogna, Chem. Eur. J.. 2013, 19, 84738477; I) N. M. Wu, H. L. Wong, V. W. Yam, Chem. Sci. 2017, 8 , 1309-1315; m) N. M. Wu, M. Ng, W. H. Lam, H. L. Wong, V. W. Yam, J. Am. Chem. Soc. 2017, 139, 15142-15150; n) J. C. Chan, W. H. Lam, H. L. Wong, W. T. Wong, V. W. Yam, Angew. Chem. Int. Ed. Engl. 2013, 52, 11504-11508; o) Z. Xu, Y. Cao, B. O. Patrick, M. O. Wolf, Chem. Eur. J. 2018, 24 10315-10319; p) N. M. Wu, M. Ng, V. W. Yam, Angew. Chem. Int. Ed. Engl. 2019, 58, 3027-3031.

[6] a) D. Seyferth, D. P. Duncan, S. C. Vick, J. Organomet. Chem. 1977, 125, C5-C10; b) D. Seyferth, S. C. Vick, M. L. Shannon, T. F. O. Lim, D. P. Duncan, J. Organomet. Chem. 1977, 135 C37-C44; c) D. Seyferth, S. C. Vick, M. L. Shannon, Organometallics 1984, 3, 1897-1905; d) D. Seyferth, M. L. Shannon, S. C. Vick, T. F. O. Lim, Organometallics 1985, 4 57-62; e) P. Boudjouk, U. Samaraweera, R. Sooriyakumaran, J. Chrusciel, K. R. Anderson, Angew. Chem. Int. Ed. 1988, 27 1355-1356; f) J. Belzner, H. Ihmels, Tetrahedron Lett. 1993 34, 6541-6544.

[7] a) W. S. Palmer, K. A. Woerpel, Organometallics 1997, 16, 4824-4827; b) W. S. Palmer, K. A. Woerpel, Organometallics 2001, 20, 3691-3697; c) A. K. Franz, K. A. Woerpel, Acc. Chem. Res. 2000, 33, 813-820.

[8] E. A. Williams, 1989. NMR Spectroscopy of Organosilicon Compounds. In: Organic Silicon Compounds (1989), (Eds. S. Patai and Z. Rappoport), pp. 511-554.
[9] a) Classical metrics for silirenes : $1.80 \AA<S i-C<1.86 \AA$ and $1.32 \AA<C-C<1.37 \AA$; b) S. Tsutsui, K. Sakamoto, C. Kabuto, M. Kira, Organometallics 1998, 17, 3819-3821; c) D. Ostendorf, L. Kirmaier, W. Saak, H. Marsmann, M. Weidenbruch, Eur. J. Inorg. Chem. 1999, 12, 2301-2307; d) B. Niepötter, D. Stalke, 2017. Chapter 1 - X-Ray Crystallography of Organosilicon Compounds (Electron Density and Chemical Bonding in Organosilicon Compounds). In: Organosilicon Compounds, (Eds. Lee, Vladimir Ya), Academic Press, pp. 3-58.

[10] a) The ${ }^{29}$ Si NMR chemical shift of siloles is strongly dependant on silicon substituents. For 1,1-dimethylsiloles, it is generally observed around $\delta \sim 5-10$, for a compilation of siloles; b) J. Y. Corey, 2011. Chapter 1 - Siloles: Part 1: Synthesis, Characterization, and Applications. In: Advances in Organometallic Chemistry, Vol. 59, (Eds. Hill Anthony F., Fink Mark J.), Academic Press, pp. 1-180.

[11] a) This low-lying orbital is typical of silole heterocycles and is usually viewed as the result of a formal $\sigma^{*}-p^{*}$ interaction within the ring; b) S. Yamaguchi, K. Tamao, J. Chem. Soc., Dalton Trans. 1998, 3693-3702; c) K. Tamao, M. Uchida, T. Izumizawa, K. Furukawa, S. Yamaguchi, J. Am. Chem. Soc. 1996, 118, 11974-11975; d) Y. Shigehiro, T. Kohei, Bull. Chem. Soc. Jpn. 1996, 69, 2327-2334; e) M. Hissler, P. W. Dyer, R. Réau, Coord. Chem. Rev. 2003, 244, 1-44.

[12] a) PPMA are prepared by postpolymerization modification of poly(pentafluorophenylmethacrylate) in the presence of propargylamine in excess; b) M. I. Gibson, E. Fröhlich, H.-A. Klok, J. Polym. Sci., Part A: Polym. Chem. 2009, 47, 4332 4345; c) G. B. H. Chua, P. J. Roth, H. T. T. Duong, T. P. Davis, A. B. Lowe, Macromolecules 2012, 45, 1362-1374.

[13] The complete NMR assignment of $10^{0.85}$ has been ascertained by comparison with the molecular compound 9 whose structure is very close to the repeating photochromic unit within $10^{0.85}$, see S42 to S51 in the Supporting Information.

[14] The degree of incorporation is determined by NMR and $85 \%$ is the maximum degree of incorporation that can be achieved from PPMA 


\section{Entry for the Table of Contents}

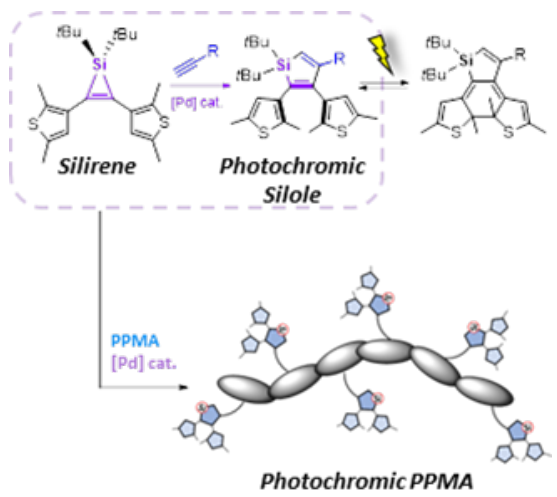

Dithienylethene Based Photochromic Siloles: a Straightforward and Divergent Synthetic Strategy. 